\title{
Soluble urokinase plasminogen activator receptor (suPAR) as an early predictor of severe respiratory failure in patients with COVID-19 pneumonia
}

\author{
Nikoletta Rovina ${ }^{1}$, Karolina Akinosoglou², Jesper Eugen-Olsen ${ }^{3}$, Salim Hayek ${ }^{4}$, Jochen Reiser ${ }^{5^{*}}$ and \\ Evangelos J. Giamarellos-Bourboulis ${ }^{6,7^{*}}$
}

Keywords: COVID-19, suPAR, Respiratory failure, Prognosis

As of April 1, 2020, 885,689 cases of infections by the novel coronavirus SARS-CoV-2 (COVID-19) have been recorded worldwide; 44,217 of them have died (https:// www.worldometers.info/coronavirus). At the beginning of the illness, patients may experience low-degree fever or flu-like symptoms, but suddenly, severe respiratory failure (SRF) emerges [1]. Increased circulating levels of D-dimers [1,2] suggest endothelial activation. Urokinase plasminogen activator receptor (UPAR) that is bound on the endothelium may be cleaved early during the disease course leading to an increase of its soluble counterpart, namely suPAR [3]. If this holds true, then suPAR may be used as an early predictor of the risk of SRF.

The Hellenic Sepsis Study Group (HSSG, www.sepsis. gr) is collecting clinical information and serum samples within the first $24 \mathrm{~h}$ of admission from patients with infections and at least two signs of the systemic inflammatory response syndrome. Since March 1, 2020, 57 patients with community-acquired pneumonia and molecular documentation of SARS-CoV-2 in respiratory secretions were enrolled. Patients were followed up daily for 14 days; the development of SRF defined as $\mathrm{PO}_{2} / \mathrm{FiO}_{2}$ ratio less than

\footnotetext{
* Correspondence: jochen_reiser@rush.edu; egiamarel@med.uoa.gr ${ }^{5}$ Department of Medicine, Rush University Medical Center, 1717 West Congress Parkway, Chicago, IL 60612, USA

${ }^{6} 4$ th Department of Internal Medicine, National and Kapodistrian University of Athens, Medical School, 12462 Athens, Greece

Full list of author information is available at the end of the article
}

150 requiring mechanical ventilation (MV) or continuous positive airway pressure treatment (CPAP) was recorded. suPAR was measured by an enzyme immunoassay in duplicate (suPARnostic ${ }^{\text {тu }}$, ViroGates, Lyngby, Denmark); the lower detection limit was $1.1 \mathrm{ng} / \mathrm{ml}$. Measurements were performed and reported by one technician who was blinded to clinical information. The study endpoint was the prognostic performance of suPAR admission levels for the development of SRF within 14 days. Measured levels were compared to those collected from 15 patients with COVID-19 from the emergency department (ED) of Rush University Medical Center.

Thirty-four (59.6\%) patients were male and 23 (40.1\%) female; the mean $\pm \mathrm{SD}$ age was $64.0 \pm 10.3$ years, and the Charlson's comorbidity index was $2.70 \pm 1.80$. The mean \pm SD admission total neutrophil count was $4414.1 \pm 2526.5 /$ $\mathrm{mm}^{3}$; the total lymphocyte count was $1149.1 \pm 1131.4$ / $\mathrm{mm}^{3}$; the C-reactive protein was $73.1 \pm 76.4 \mathrm{mg} / \mathrm{l}$. Admission levels of suPAR were significantly greater among patients who eventually developed SRF (Fig. 1a). Circulating levels of suPAR were of the same range as those of the US cohort (Fig. 1b). Receiver operator characteristics curve analysis identified levels $\geq 6 \mathrm{ng} / \mathrm{ml}$ as the best predictor for SRF. At that cutoff point, the sensitivity, specificity, positive predictive value, and negative predictive value for the prediction of SRF was $85.7 \%, 91.7 \%, 85.7 \%$, and $91.7 \%$, respectively. The time to SRF was much shorter among patients with $\operatorname{suPAR} \geq 6 \mathrm{ng} / \mathrm{ml}$ (Fig. 1c). The only admission 


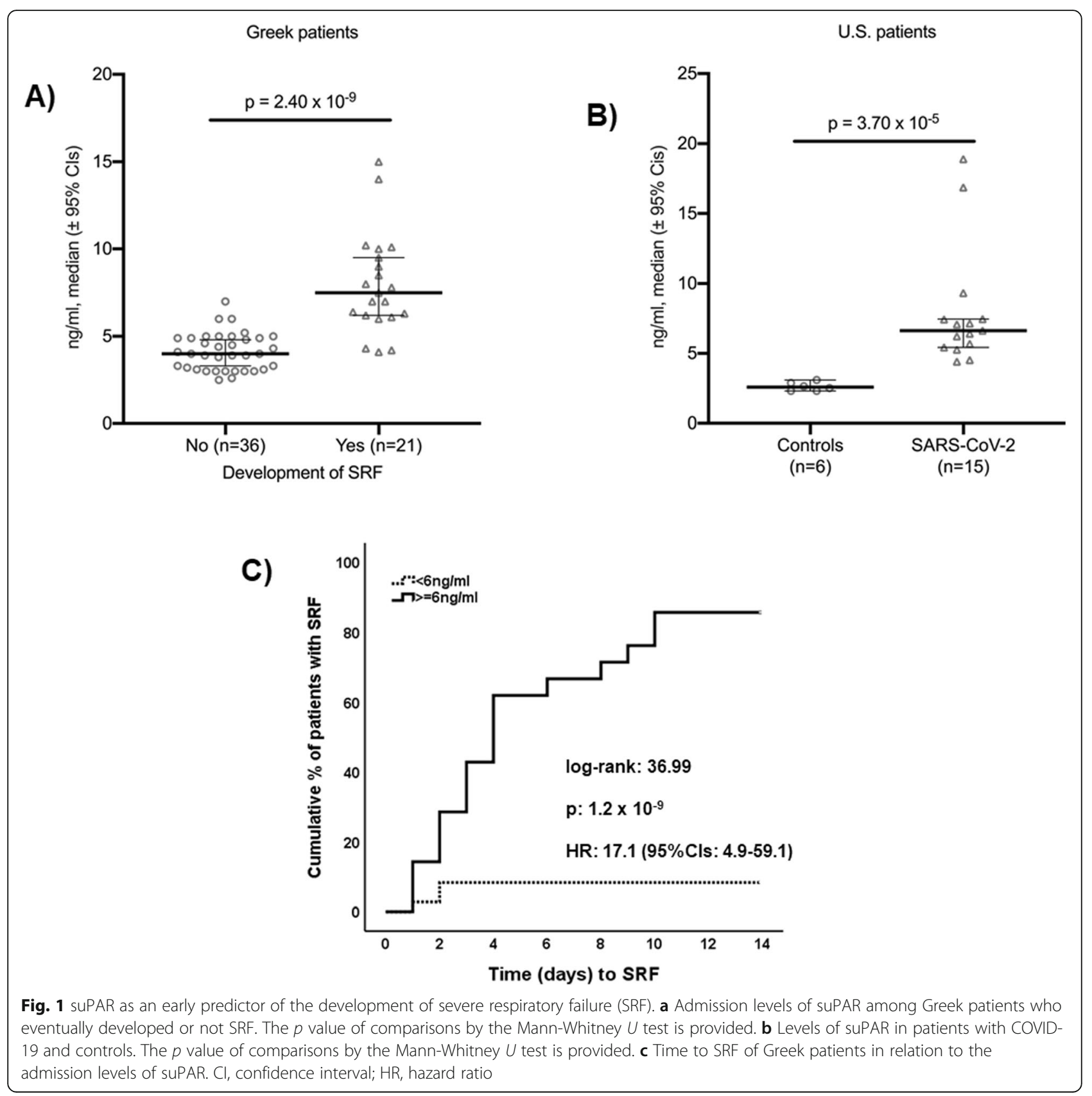

Table 1 Independent variables at admission associated with the development of severe respiratory failure

\begin{tabular}{|c|c|c|c|c|c|c|}
\hline & \multirow{2}{*}{$\begin{array}{l}\text { No need for } \\
\text { MV or CPAP, n (\%) }\end{array}$} & \multirow{2}{*}{$\begin{array}{l}\text { Need for MV } \\
\text { or CPAP, n (\%) }\end{array}$} & \multicolumn{2}{|l|}{ Univariate analysis } & \multicolumn{2}{|c|}{ Forward Cox regression analysis } \\
\hline & & & OR (95\%Cls) & $\overline{p \text { value }}$ & HR $(95 \% \mathrm{Cls})$ & $p$ value \\
\hline Male gender & $15(41.7)$ & $19(90.5)$ & $0.07(0.02-0.37)$ & $<0.0001$ & $7.80(1.75-34.76)$ & 0.007 \\
\hline $\mathrm{CCl}>2$ & $17(48.6)$ & $17(77.3)$ & $7.00(2.11-24.25)$ & 0.002 & & ns \\
\hline suPAR $\geq 6 \mathrm{ng} / \mathrm{ml}$ & $3(8.3)$ & $18(85.7)$ & $66.00(12.05-361.35)$ & $<0.0001$ & $16.43(4.56-59.19)$ & $<0.0001$ \\
\hline Neutrophils $\geq 4200 / \mathrm{mm}^{3}$ & $8(22.2)$ & $16(72.2)$ & $11.20(3.13-40.08)$ & $<0.0001$ & & ns \\
\hline $\mathrm{CRP} \geq 58 \mathrm{mg} / \mathrm{l}$ & $7(19.4)$ & $13(61.9)$ & $6.73(2.01-22.51)$ & 0.002 & & ns \\
\hline
\end{tabular}

CCI Charlson's comorbidity index, CRP C-reactive protein, $C I$ confidence interval, $H R$ hazard ratio, OR odds ratio 
variables that were independently associated with the development of SRF were male gender and suPAR $\geq 6 \mathrm{ng} / \mathrm{ml}$ (Table 1). A positive association was found between admission suPAR and D-dimers $\left(r_{\mathrm{s}}=+0.777, p<0.0001\right)$.

suPAR has been proposed as a biomarker for the risk of death. An analysis of the TRIAGE III trial in 4420 patients admitted at the ED in Denmark revealed that suPAR ranged between 2.6 and $4.7 \mathrm{ng} / \mathrm{ml}$ in 30-day survivors and between 6.7 and $11.8 \mathrm{ng} / \mathrm{ml}$ in 30-day nonsurvivors [4]. Early increase of suPAR has also been reported to be a prediction of 28-day outcome in sepsis [5]. UPAR is bound to the endothelial membrane and functions for the differential signaling between the cleaved and uncleaved forms of kininogen [3]. The positive association between D-dimers and suPAR suggest early complex kininogen and UPAR interactions at the endothelial level of early stages of COVID-19. Higher plasma levels of suPAR are predictive of and potentially causally involved in kidney disease [6] which can be a feature of severe COVID-19 infection.

Findings suggest that suPAR may early trace patients who need intensified management probably in need of anti-inflammatory treatment [6]. Whether modification of circulating suPAR is a useful therapeutic option will require further study.

\section{Abbreviations}

CCl: Charlson's comorbidity index; Cl: Confidence interval; COVID19: Infection by the novel coronavirus SARS CoV-2; CPAP: Continuous positive airway pressure treatment; HR: Hazard ratio; MV: Mechanical ventilation; NPV: Negative predictive value; PPV: Positive predictive value; ROC: Receiver operating characteristic; SD: Standard deviation; SRF: Severe respiratory failure; suPAR: Soluble urokinase plasminogen activator receptor

\section{Acknowledgements}

Not applicable

\section{Authors' contributions}

NR and KA contributed in the collection and analysis of clinical data, critically revised the manuscript, and gave final approval of the version to be published. JEO and JR conceptualized the study design, contributed to the analysis of the data, critically reviewed the manuscript, and gave final approval of the final version to be published. SH participated in study design and data interpretation, critically reviewed the manuscript, and gave final approval of the final version to be published. EJGB conceptualized the study design, contributed to the analysis of the data, wrote the manuscript, critically reviewed the manuscript, and gave final approval of the version to be published.

\section{Funding}

The study was funded by unrestricted educational grants provided by the Hellenic Institute for the Study of Sepsis. Funds were also provided by Rush University Medical Center.

\section{Availability of data and materials}

The datasets used and/or analyzed during the current study are available from the corresponding author upon reasonable request.

\section{Ethics approval and consent to participate}

Written informed consent was provided from all participants. The study was approved by the Ethics Committees of the following hospitals:
- Ethics Committee of ATTIKON University General Hospital (approval of 26.02.2019)

- Ethics Committee of Sotiria Athens General Hospital (approval number 23/12.08.2019)

- Ethics Committee of Rion University General Hospital (approval 19956/ 29.07.2008)

- Institutional Review Board of Rush University Medical Center (approval \# IRB14051401-IRB01)

\section{Consent for publication}

Not applicable

\section{Competing interests}

JEO is a co-founder, shareholder, and CSO of ViroGates A/S, Denmark. JEO is an inventor on patents on suPAR owned by Copenhagen University Hospital Hvidovre, Denmark.

$J R$ is a co-founder and shareholder of Trisaq, a biopharmaceutical company that develops drugs that target suPAR.

EJGB has received honoraria from AbbVie USA, Abbott $\mathrm{CH}$, InflaRx GmbH MSD Greece, XBiotech Inc., and Angelini Italy; independent educational grants from AbbVie, Abbott, Astellas Pharma Europe, AxisShield, bioMérieux Inc., InflaRx GmbH, and XBiotech Inc;; and funding from the FrameWork 7 program HemoSpec (granted to the National and Kapodistrian University of Athens), the Horizon2020 Marie-Curie Project European Sepsis Academy (granted to the National and Kapodistrian University of Athens), and the Horizon 2020 European Grant ImmunoSep (granted to the Hellenic Institute for the Study of Sepsis).

All other authors have disclosed that they do not have any conflicts of interest relevant to this submission.

\section{Author details}

${ }^{1} 1$ st Department of Pulmonary Medicine and Intensive Care Unit, National and Kapodistrian University of Athens, Medical School, 11527 Athens, Greece. ${ }^{2}$ Department of Internal Medicine, University of Patras, Medical School, 26504 Rio, Greece. ${ }^{3}$ Clinical Research Centre, Copenhagen University Hospital, Hvidovre, Denmark. ${ }^{4}$ Department of Medicine, University of Michigan, Ann Arbor, Ml 48103, USA. ${ }^{5}$ Department of Medicine, Rush University Medical Center, 1717 West Congress Parkway, Chicago, IL 60612, USA. ${ }^{6} 4$ th Department of Internal Medicine, National and Kapodistrian University of Athens, Medical School, 12462 Athens, Greece. ${ }^{7} 4$ th Department of Internal Medicine, ATTIKON University Hospital, 1 Rimini Street, 12462 Athens, Greece.

Received: 6 April 2020 Accepted: 14 April 2020

Published online: 30 April 2020

\section{References}

1. Guan W, Ni ZY, Hu Y, Liang WH, Ou CQ, He JX, et al. Clinical characteristics of coronavirus disease 2019 in China. N Engl J Med. 2020. https://doi.org/10. 1056/ NEJMoa2002032.

2. Pixley RA, Espinola RG, Ghebrehiwet B, Joseph K, Kao A, Bdeir K, et al. Interaction of high-molecular-weight kininogen with endothelial cell binding proteins suPAR, gC1qR and cytokeratin 1 determined by surface plasmon resonance (BiaCore). Thromb Haemost. 2011;105:1053-9.

3. Schultz M, Rasmussen LJH, Høi-Hansen T, Kjøller E, Jensen BN, Lind MN, et al. Early discharge from the emergency department based on soluble urokinase plasminogen activator receptor (suPAR) levels: a TRIAGE III substudy. Dis Markers. 2019;2019:3403549.

4. Hayek SS, Leaf DE, Samman Tahhan A, Raad M, Sharma S, et al. Soluble urokinase receptor and acute kidney injury. N Engl J Med. 2020;382:416-26.

5. Giamarellos-Bourboulis EJ, Norrby-Teglund A, Mylona V, Savva A, Tsangaris I, Dimopoulou l, et al. Risk assessment in sepsis: a new prognostication score by APACHE II score and serum soluble urokinase plasminogen activator receptor. Crit Care. 2012;16:R149.

6. Mehta P, McAuley DF, Brown M, Sanchez E, Tattersall RS, et al., 2020. COVID19: consider cytokine storm syndromes and immunosuppression. Lancet https://doi.org/10.1016/S0140-6736(20)30628-0.

\section{Publisher's Note}

Springer Nature remains neutral with regard to jurisdictional claims in published maps and institutional affiliations. 